\title{
Research on the Patent Strategy
}

\section{C.Q. GAO , W. CHEN \& J.H. SUN}

School of Mechanical Engineering, University of Jinan, No.336 Nanxinzhuang West Road, Jinan, Shandong, P.R. China

ABSTRACT: In the modern era of knowledge economy, patent is the knowledge carriers of new techniques and patent war becomes more intense. The generation of enterprise patent strategy is to conform to this trend. The key factor of keeping competitive marketplace and innovation is to build basic structure, content and process of patent strategy. Patent strategy includes protection, introduction, cooperation and avoidance strategies. This paper discusses the application of TRIZ theory on patent avoidance.

KEYWORD: Patent; Strategy; TRIZ; Patent around

\section{INTRODUCTION}

Patent is an important part of intellectual property and a crucial intangible assets. Competition among international technology economy is outstanding performance for the patent competition.

"Patent strategy" and "Core competition of enterprise" are hot areas of research in the modern theoretical circles. Cross-border disputes caused by intellectual property continuously appear. Several intellectual property and patent dispute show that foreign companies are stepping up efforts to implement patent strategy for Chinese enterprises. Patent is becoming the most effective tool that they check Chinese enterprises and expand products of domestic and international markets. Patent has become a core strategy that multinational companies scramble for global market and form comprehensive competitiveness. Statistics of '337 investigation' of USA form 2002 to 2005 is shown in Table 1. The ratio of amount of '337 investigation' for Chinese enterprises to Global enterprises became more [1].

Table 1. Statistics of '337 investigation' of USA form 2002 to 2005.

\begin{tabular}{|c|c|c|}
\hline Year & $\begin{array}{l}\text { Amount of '337 } \\
\text { investigation' for Chinese } \\
\text { enterprises }\end{array}$ & $\begin{array}{l}\text { Amount of '337 } \\
\text { investigation' for Global } \\
\text { enterprises }\end{array}$ \\
\hline 2005 & 10 & 21 \\
\hline 2004 & 11 & 26 \\
\hline 2003 & 8 & 18 \\
\hline 2002 & 5 & 17 \\
\hline Sum & 24 & 82 \\
\hline
\end{tabular}

\section{ENTERPRISE PATENT STRATEGY}

The patent system is a legal system of science and technology which developed with the development of production. And it is also a management system [2] that use legal and economic means to promote technological progress.

The principal body of patent system is a patent. The main purpose of the patent system is to encourage and protect invention and creation, and provide legal protection and other various conveniences for patent.

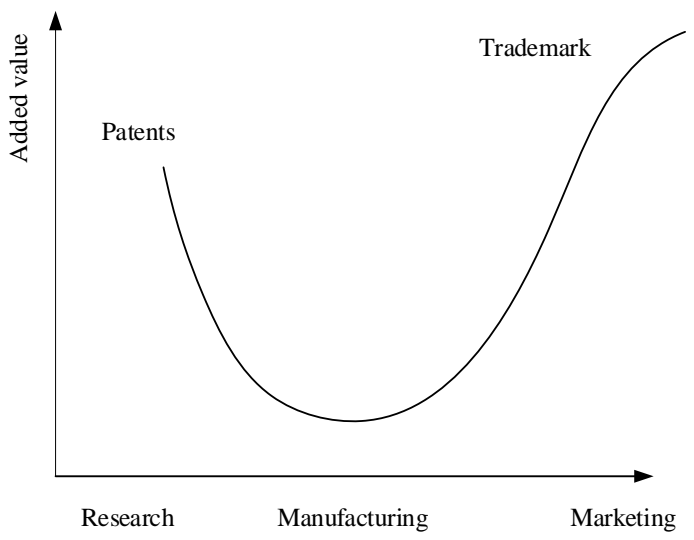

Figure 1. Smile curve.

Patent strategy is related to policy and method [3] with long-term plan and whole conscious thought, which made in order to promote the patent technology development and technological innovation, analyze the development of the competitors, protect the legitimate rights and interests of their own enterprises, legally and 
reasonably learn from experience and technology of others and strive for long-term survival and constant development in this world full of fierce competition. Smile curve is shown in Figure 1. Patents and trademark can get more added value than manufacturing process [1].

Enterprise is the main competition body of our socialist market economic system. In the exiting environment of our market economic system, this requests enterprise must follow the rules of market economic and aim to establish a modern enterprise system. Then neatly and tactfully participate in the competition with foreign companies and seek its own development. Patent system is a bridge between technology and market. It serves the market and highly valued to protect domestic enterprises, and even the patent work has become an important factor which decided to enterprise survival and development.

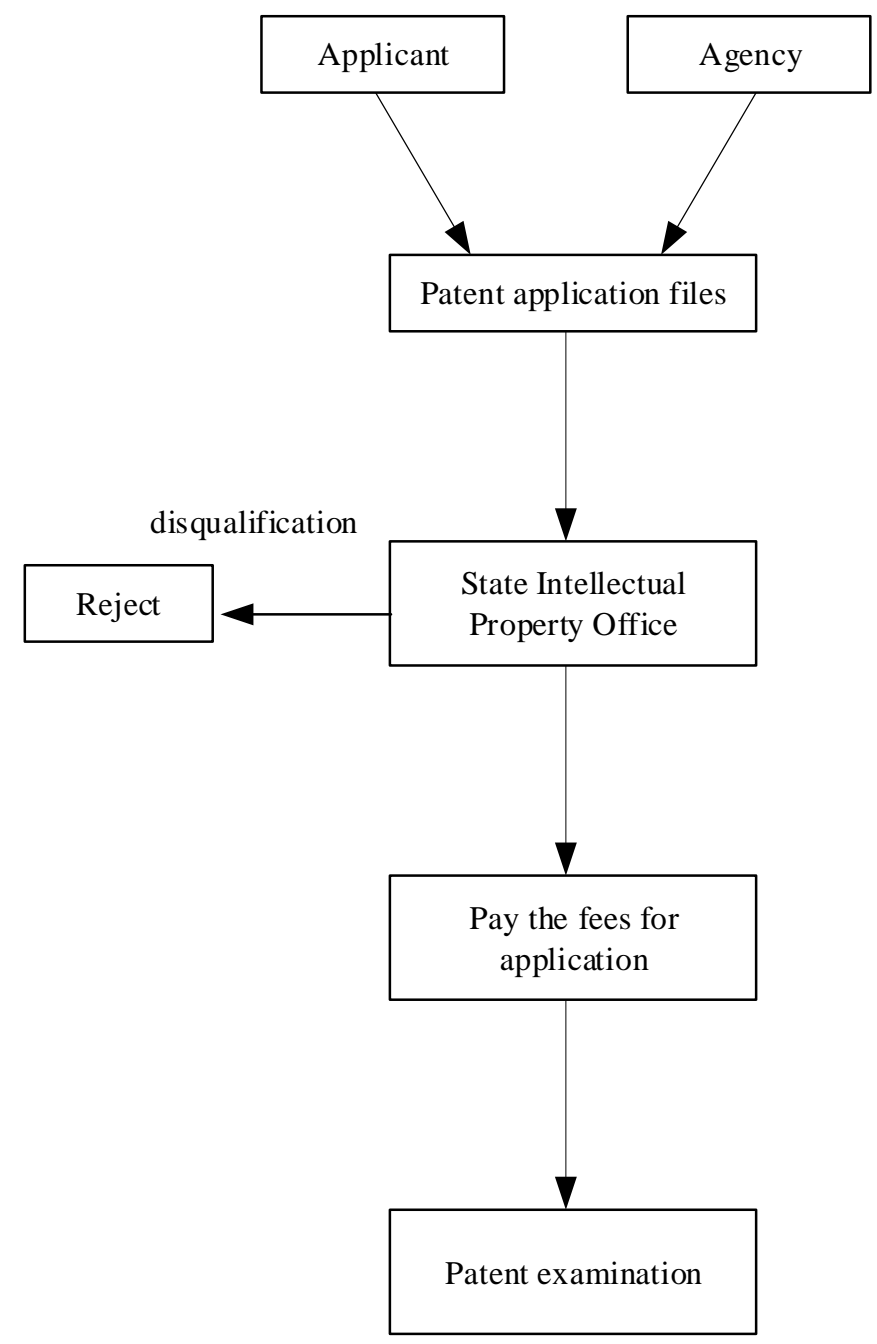

Figure 2. Process of patent application.

It is not hard to see from the economic situation at home and abroad, enterprise technology competition is more intense and international. This decided the enterprises operating performance of different countries, so the management of enterprises must adapt to those two characteristics. Competition is always the topic of enterprise management. The essence of enterprise competition is technology competition, and only continuous innovation and advancement of technology can provide a steady stream of power for enterprise competition. It is obvious that protection of technological innovation has been on the agenda of the enterprise prosperity. Only using the patent and enterprise management strategy in accordance with the law, we can ensure the place of enterprises in economic activities. The content of enterprise patent strategy is more extensive, but the establishment of complete patent system should not be ignored. The process of patent application is shown in Figure 2 [1].

\section{THE CONTENT OF PATENT STRATEGY}

\subsection{Reasonable protection of our own patent}

The improvement of patent system is very important to encourage innovation. The level of patent protection is directly related to the effective protection rates of legitimate rights. And it also plays an important role to balance technology innovation and imitation. The goal of patent system is how the patentee or others need to be protected reasonably protect their own patent right.

(1) First of all, taking enterprise as an example, weak striking force on patent infringement caused the prominent question patent infringement. This suggest that the patent rights is difficult to get reasonable protection. Applying for protection strategy has become one of the most important ways to protect patent rights. In order to protect our own patent better, we can appropriate popularization application and patent information to the public in details to encourage the patentee to apply for authorization in time ${ }^{[4]}$.

(2) Next, we should expand the scope of patent application. For the same patents, we can respectively apply from invention, utility and industry design patents. Although we can only determine one form at last, this method can improve the efficiency of patent application, at the same time it is beneficial to protect our own patent rights.

(3) Then we should dare to take action and compensation to patent infringement of others. Through analyzing the lawsuit scores given by enterprise, we find that most subjects of right doubt the way to protect the rights in judicial way. The reason is that enterprise generally believed that the effectiveness of law enforcement should be improved. But comparing the legal tools with personal protection, the former has coerciveness and conditionality. Judicial system is not perfect in our modern country. Patent right objects should believe and agree with the judicial way to protect their legal rights, meanwhile actively fight against piracy with enforcement tools to protect legitimate rights and interests. 
(4) Finally, we should analyze technology evolution trend and protect those future technologies. For an existing technology, though retrieve, analyze and summarize the related patent dates, we can obtain the level of patent and the number of patent in different time. Marking those information in coordinator system in chronological order, we can get relationship between time and product performance, the number of patent, the level of patent, profits. Four curves will be compared with the standard curve. Through the comparison we can determine the position of existing technology and the stage of product life circle, and predict the direction of technology evolution. Then we can apply for protection for the future technology.

\subsection{Introduction of patent and innovation strategy}

(1) The introduction of patent technology is a constant selection process, so the introduction of necessary patent technology become an important issue. We can understand the technology results and price though a lot of investigation, thus choosing which technology should be introduced. The researches mainly include technique trends of its own domain, advanced technology in the same industry, technical feasibility. We can make a general outline and positioning for the technology will be introduced, then choose from a variety of patents [5].

(2) Aiming at the patent that may violate our rights, we should take some flexible remedial measures, such as purchase, introduction or cooperation. Technological introduction is a technology introduction link that should not be ignored. In the process of cooperation, we can learn some good management mode. The enlightenment of training orientation is significant for using techniques and autonomously developing new techniques.

(3) Do not ignore the innovation and protection of our existing patent technology while we pay more attention to the introduction of technology. Insist on the policy of self-reliance, we can efficiently prevent domestic market being preempted by foreign enterprise and protect the produce profit of domestic enterprise and be ready for everything that will be happen. Introduce foreign technology properly could improve competitiveness of domestic enterprises efficiently. Facts proved that the adjustment of new product quality is an efficient measure which make optimized profit for domestic enterprises. This requires that domestic enterprises make full use of local advantages and seek for excellence in every link of technology. Thus we can produce more high quality product with stronger competitiveness and maintain the competitiveness of the enterprise management.

\subsection{Patent around design used of law and policy}

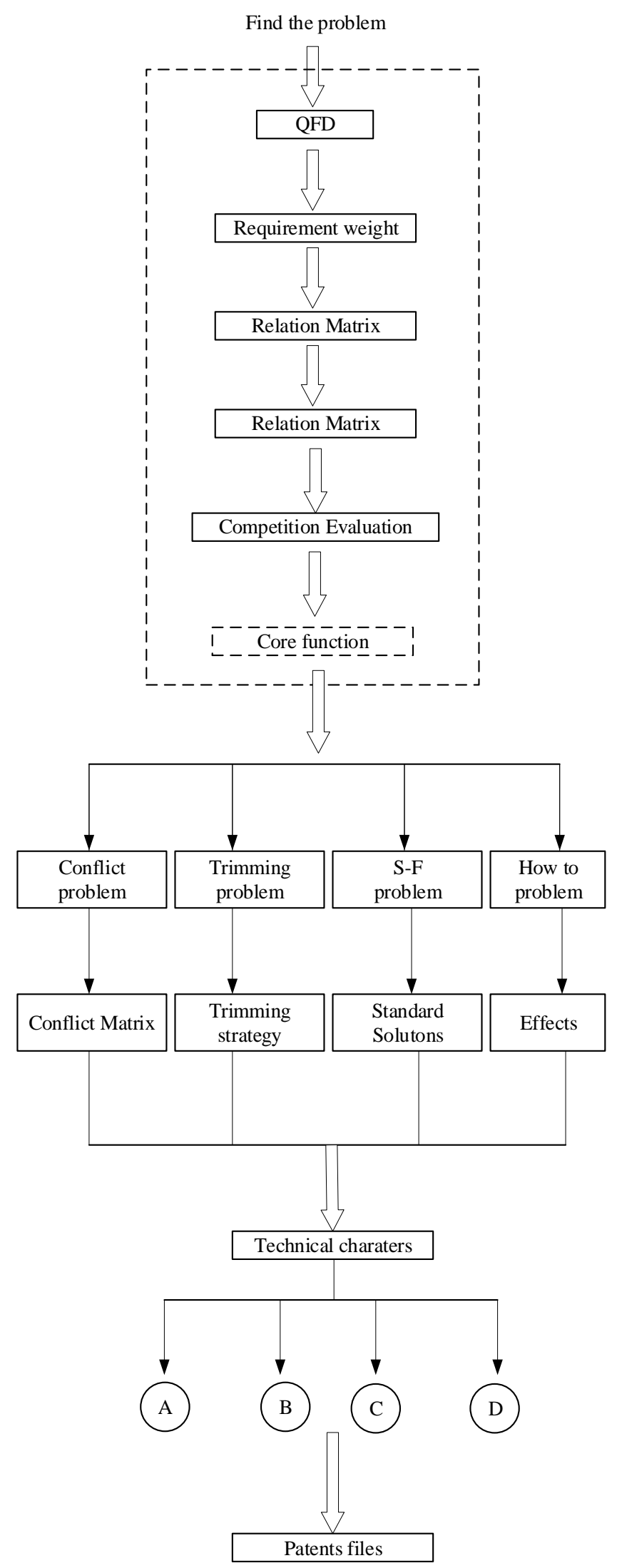

Figure 3. The design process of patent around combine QFD and TRIZ.

Around design is a breakthrough of patent technology monopoly and a benefit embodiment of patent system. It encourages competition and promotes the technological innovation. Competitors can obtain inspiration from the innovative ideas of 
barriers patent, and avoid using the technical scheme which is protected by this right. Then we can constantly create new scheme on the basis of barriers patent and make technological innovation.

\begin{tabular}{|c|c|c|c|}
\hline \multirow{2}{*}{$\begin{array}{l}\text { The principle } \\
\text { of } \\
\text { infringement } \\
\text { verdict }\end{array}$} & \multicolumn{2}{|c|}{$\begin{array}{l}\text { The diagram of } \\
\text { patent around }\end{array}$} & \multirow[t]{2}{*}{$\begin{array}{l}\text { Clipping of } \\
\text { technology system }\end{array}$} \\
\hline & $\begin{array}{l}\text { Patent } \\
\text { techrical } \\
\text { character } \\
\text { istic }\end{array}$ & $\begin{array}{l}\text { Around } \\
\text { scheme }\end{array}$ & \\
\hline $\begin{array}{l}\text { The principle } \\
\text { of universal } \\
\text { coverage }\end{array}$ & & & $\begin{array}{l}\text { Clipping methodcut } \\
\text { one or more than one } \\
\text { techrical } \\
\text { characteristics }\end{array}$ \\
\hline \multirow[t]{3}{*}{$\begin{array}{l}\text { The principle } \\
\text { of equality }\end{array}$} & & & $\begin{array}{l}\text { Replacement } \\
\text { methodreplace one } \\
\text { or more than one } \\
\text { techrical } \\
\text { characteristics }\end{array}$ \\
\hline & & & $\begin{array}{l}\text { Combination } \\
\text { method combine and } \\
\text { replace one or more } \\
\text { than one technical } \\
\text { characteristics }\end{array}$ \\
\hline & & & $\begin{array}{l}\text { Decomposition } \\
\text { methoddecompose } \\
\text { and replace one or } \\
\text { more than one } \\
\text { techrical } \\
\text { characteristics }\end{array}$ \\
\hline
\end{tabular}

Figure 4. Function clipping method apply to patent around.

In law, we should improve and protect the system of intellectual property includes three aspects:(1) to protection mechanisms and restriction mechanisms of intellectual property, legislative content and detail;(2) to make full use of judicial coping mechanisms and combine theory with practice based on the principle of law; (3) to make effective use of regulation of intellectual property laws and exclude intellectual property trap. Actually if ignore the results of circumvention, the patentee can always put to the proof "unintentional violation".

In policy, we should establish complete patent system and create technology standards and participate in the formulation of international technology standards. Our own should support the domestic enterprises and help them. It is not difficult to see that china's policy is short of efficient institutional arrangement from a lot of patent cases. When enterprises get into intellectual property disputes, the government can play a good role. For example, Hisense elegantly solved the dispute with the aid of government, public opinion and market forces. So the former policy of service is better for the establishment of domestic enterprises and dispose of follow-up mechanism. The design process of patent around combining QFD and TRIZ is shown in Figure 3.

\section{METHOD OF PATENT AROUND DESIGN}

We can make an around design with the help of aid measures, such as retrieval tools and TRIZ. When omit or revamp more than one characteristics of right expecting, we can retrieve the functions aimed at a technical characteristic that will be replaced, and then get the characteristics of substitution technique. We can use it to get around scheme. Besides, TRIZ innovation theory also provide some basic principles, which can be used to inspire innovative ideas of designers.

TRIZ theory of inventive problem solving provided a series of effective tools and methods for patent around design [6]. Function trimming method applied to patent around is shown in Figure 4.

\section{CONCLUSIONS}

(1) Enterprise patent strategy protected the key techniques of enterprises with patent protection methods and patent information from patent system. It seeks the biggest economic benefits for the enterprise. Reasonable patent strategy has an important significance to the survival and competition of enterprises.

(2) TRIZ is an effective innovative theory and it provides a method and theory for patent around and technical innovation. Technical clipping method and around design form the corresponding process.

\section{ACKNOWLEDGEMENT}

This work was financially supported by Science and Technology Development Plan Project of Shandong Province (2014GGX106003), Large Equipment Upgrade Project of Shandong Province (2012SJGZ15).

\section{REFERENCES}

[1] Yuan zhenfu. Management of Patent running. Beijing: . Intellectual Property Publishing House, 2011.

[2] Feng Xiaoqing. Discussion on Enterprise Patent Strategy. Henan School Science, 2007,03:91-95.

[3] Lin Haohui. Research on the Patent Strategy of Chinese Enterprises. Guangdong University of Technology, 2004.

[4] Zhu Xuezhong, Chen Rongqiu. Economic Analysis on Patent Protection. Science Research Management, 1999,02:62-68.

[5] Yu Xiang, Yao Li. Patent Strategy in Technology Importing. Technological Process and Countermeasures, 2004,04:23-25.

[6] Jiang Ping, Luo Pingya, Sun Jianguang, Tan Runhua. Method about Patent Design Around Based on Function Trimming. Journal of Mechanical Engineering, 2012, $11: 46-54$. 